\title{
O futuro da democracia na Europa. Direitos e poderes na economia global ${ }^{1}$
}

\section{Luigi Ferrajoli}

Professor de Filosofia do direito e Teoria geral do direito na Università Roma Tre, Itália. I.ferrajoli@giur.uniroma3.it

\section{A CRISE DA POLÍTICA E DA DEMOCRACIA POLÍTICA}

Considero de extraordinária atualidade a passagem de Lelio Basso lembrado por Elena Paciotti na abertura do nosso seminário: “Andamos em direção de um mundo em que o poder de poucas centenas de homens (...) kafkianamente distantes e inacessíveis, e em alguns casos inclusive desconhecidos, imporão a bilhões de outros homens sobre a Terra a escolha entre... serem eliminados ou marginalizados, ou também fazerem-se cúmplices... do aparato de domínio”. Parece a descrição, incrivelmente antecipadora, do que está ocorrendo hoje. É a mesma tese expressa pelo movimento dos ocupantes de Wall Street: "Somos os 99\% governados por

\footnotetext{
${ }^{1}$ Conferência proferida no Seminário Il Futuro della Democrazia in Europa, realizado na Fondazione Basso, Roma, Itália, nos dias 9 e 10 de dezembro de 2011. Tradução do italiano por Alfredo Copetti Neto e Doglas Cesar Lucas.
} 
1\% da população que, como escreveu Joseph Stiglitz, "controla mais de $40 \%$ da riqueza”, graças a "sistemas fiscais nos quais um bilionário como Warren Buffett paga menos tributos do que sua secretária e os especuladores, que contribuíram para o colapso da economia global, têm imposições fiscais mais baixas do que aqueles que trabalham para viver".

Bastaria isso para assinalar a dissolução da democracia política, mas existe um segundo aspecto ainda mais profundo da crise que estamos vivendo. Esta é uma crise anterior à crise da democracia, é uma crise do Estado moderno, entendido o Estado como esfera pública destinada à defesa dos interesses públicos, separada da economia e em relação a esta heterônoma e supraordenada. E se manifesta na total impotência da política e na sua subalternidade à economia, aos assim chamados "mercados", quer dizer, aos poderes desregulados do capital financeiro especulativo, que depois de terem provocado a crise econômica e de serem salvos pelos Estados, ameaçam o falimento dos próprios Estados que os haviam salvo e impõem a eles a destruição do Welfare, a redução da esfera pública, o desmantelamento do direito do trabalho, o crescimento das desigualdades e da pobreza e a devastação dos bens comuns. Ocorreu nos Estados Unidos e está hoje ocorrendo na Europa. Assistimos, assim, a um paradoxo. O mercado sem regras, suportado por aquele pensamento único que é a ideologia liberista, depois de ter sido a causa da crise - na ausência de políticas capazes de governá-lo -, propõe-se hoje como a terapia: uma terapia destrutiva, também sobre o plano econômico, na medida em que agrava as próprias causas da crise, a começar pela maior pobreza e pelas restrições do poder aquisitivo e dos direitos sociais, dando vida a uma espiral recessiva incontrolada. Assim inverteu-se a relação entre público e privado: não mais o governo dos poderes privados por parte dos poderes públicos, mas o governo dos poderes públicos por parte dos poderes privados. E assim inverteu-se a relação entre política e economia. Não são mais os Estados, com suas políticas, que disciplinam os mercados, impondo suas regras, limites e vínculos, mas são os mercados que discipli- 
nam e governam os Estados. Não são mais os governos e os parlamentos democraticamente eleitos que regulam a vida econômica em função dos interesses gerais, mas são os mercados que impõem aos Estados políticas antidemocráticas e antissociais, para a vantagem dos interesses privados da maximização dos lucros, das especulações financeiras e da rapina dos bens comuns e vitais.

É essa a crise sistêmica que está deteriorando a democracia ocidental: a substituição do governo político e democrático da economia pelo governo econômico e obviamente não democrático da política. Trata-se, repito, de uma crise epocal não somente da democracia, mas também do Estado como instituto e política separada e supraordenada à economia. A separação entre sociedade civil e Estado, entre economia e política, é um traço característico da modernidade jurídica e política que faz parte do constitucionalismo profundo do Estado moderno, em oposição ao Estado patrimonial do Ancien Régime. Não por acaso o Estado moderno nasce conjuntamente com o capitalismo, como instituição política separada da sociedade e como esfera pública heterônoma em relação aos poderes econômicos, por sua natureza incapazes de se regularem autonomamente. Por isso podemos falar de um regresso pré-moderno ao Estado patrimonial, determinado pela derrocada da relação entre poderes econômicos e poderes políticos de governo, não mais os primeiros subordinados e regulados pelos segundos, mas vice-versa: pelos conflitos de interesses e as múltiplas formas de corrupção e de condicionamento lobista, pela hegemonia do pensamento único liberista, mas também pela assimetria entre o caráter inevitavelmente local dos poderes estatais e o caráter global dos poderes econômicos e financeiros.

Tudo isso esta pondo em evidência um terceiro aspecto da crise do Estado - a crise do Estado de Direito, quer dizer da subordinação ao direito dos poderes públicos -, que tem suas raízes nas próprias origens do Estado moderno. O paradigma do "Estado de Direito”, como a própria expressão 
diz, desenvolveu-se somente nos confrontos desse mesmo Estado, ou seja, dos poderes estatais. Não se direcionou nem contra os poderes supraestatais (tendo o Direito Positivo sido identificado, por longo tempo, com somente o Direito Estatal), e tampouco contra os poderes econômicos privados, por sua vez, ideologicamente concebidos pela tradição liberal de Locke a Marshall - não como poderes, mas como direitos de liberdade. Desde então aparece a impotência dos Estados, capazes somente de dar respostas locais a problemas globais. Não intencionalmente. O Estado de Direito, nas formas hodiernas do Estado de Direito Constitucional, foi-se esvaziando também em relação aos poderes públicos estatais, em razão de um verdadeiro processo desconstituinte, manifestando-se, na Itália, não somente nas violações e nas tentativas de reforma da carta de 1948, mas em um ataque ao constitucionalismo enquanto tal, quer dizer, como um sistema de limites e vínculos aos poderes políticos e majoritários e na reivindicação populista da onipotência das maiorias. À impotência da política em relação aos poderes selvagens dos mercados correspondeu a reivindicação da onipotência da política à custa dos direitos dos cidadãos, que se manifestou na agressão aberta, para fazer frente à crise, de um lado ao Estado social, de outro ao trabalho: de um lado aos direitos sociais, de outro ao direitos dos trabalhadores, ambos constitucionalmente garantidos.

Pensemos na Itália, mas não somente na Itália, na agressão ao trabalho, indicado pelo artigo $1^{\circ}$ da Constituição Italiana - da qual não por acaso foi proposta a ab-rogação - como o fundamento da república. $\mathrm{O}$ velho direito do trabalho, com os seus direitos e as suas garantias conquistadas por meio de dezenas de lutas, dissolveu-se, na Itália, por uma série de contrarreformas: a substituição da contratação coletiva pela contratação individual, o abandono dos velhos modelos de relações trabalhistas por tempo indeterminado em favor de uma multiplicidade de relações de trabalho individuais, atípicos, flexíveis, precários, ocasionais, e, por isso, privados de garantias; a desvalorização do trabalho e dos trabalhadores, 
reduzidos, como no século 19, as mercadorias competindo entre si; a neutralização do conflito social e a divisão do mundo do trabalho e dos sindicatos mediante a imposição aos trabalhadores, segundo o modelo Fiat, da renúncia aos seus direitos sob a chantagem de demissão. Expressões como "classe operária" e "movimento operário" estão não por acaso fora de uso, sendo deixadas de lado a partir da precariedade das relações de trabalho, a velha solidariedade de classe e a própria subjetividade política dos trabalhadores, ambas fundadas a partir da igualdade nas condições de trabalho e nos direitos e, por isso, sobre a autorrepresentação do trabalhador como pertencente a uma comunidade de iguais.

\section{UM VAZIO DE DIREITO. DIREITO E PODER}

Encontramo-nos então diante de uma crise econômica que está provocando, mas também em parte levando a uma crise tripla: da democracia política, do Estado moderno como esfera pública separada e supraordenada à economia e do Estado Constitucional de Direito como sistema de limites e vínculos a todos os poderes.

A crise, revelada primeiramente nos países pobres atingidos pela dívida externa e hoje extensiva também às grandes democracias ocidentais, manifesta-se, em primeiro lugar, como crise do Estado Nacional Soberano determinada, por um lado, pelos processos de globalização. Democracia representativa e Estado de Direito nasceram, de fato, e se desenvolveram internamente aos Estados e aos territórios nacionais e sobre a base de uma substancial identificação do Direito com o Direito estatal. Ambos, assim, entraram em crise pelo desenvolvimento dos poderes econômicos transnacionais que não se submeteram ao controle dos governos nacionais e, portanto, aos vínculos legais impostos pelos ordenamentos estatais, rompendo, com isto, o duplo nexo entre democracia e povo e entre poder e direito, tradicionalmente mediado pela representação política e pelo pri- 
mado da lei estatal votada pelas instituições representativas. O principal efeito da crise dos velhos estados nacionais é o vazio de direito público, ou seja, a falta de regras públicas, de limites e de vínculos voltados à garantia dos direitos humanos nos confrontos com os novos poderes transnacionais que têm derrubado os velhos poderes estatais ou que os subtraiu ao seu papel de governo e de controle.

É aqui que se mostra a atualidade do pensamento de Lelio Basso. $\mathrm{O}$ verdadeiro conflito, bem mais que e bem além da relação entre capital e trabalho, ocorre entre os povos e o poder. E para limitar e hastear o poder, o instrumento essencial é o Direito. É esta a originalidade de Basso em relação à inteira tradição marxista. $\mathrm{O}$ Direito, como já se observou, pode ser não somente um instrumento de domínio e de defesa dos interesses da classe dominante. Não é somente a lei do mais forte, segundo a escolástica leninista expressa por Visinski. Ele pode ser a lei do mais fraco, no momento em que ele for formulado a partir dos direitos fundamentais dos povos e dos indivíduos. Não somente isso. O Direito é a linguagem pela qual pensamos os problemas e as suas soluções. E é também a única técnica por meio da qual é possível limitar e regular os poderes, caso contrário, selvagens. Disso é prova a intolerância em relação ao Direito não somente das autocracias políticas, mas também dos poderes do mercado, cujo atual domínio é gerado justamente pela falta de limites e de vínculos jurídicos à sua altura.

\section{O FUTURO DO ESTADO DE DIREITO E DO CONSTITUCIONALISMO}

Não é possível prever o êxito desta crise. Sabemos somente que isso dependerá, como sempre, do papel que serão capazes de desenvolver a política e a razão jurídica. O futuro do Estado de Direito dependerá da refundação ou da ulterior dissolução da legalidade - ordinária e constitucional, estatal e supraestatal - à altura dos desafios a ele impostos pelos 
dois aspectos da crise anteriormente ilustrados. Certamente não poderão ser restaurados ou repristinados nem o Estado nacional nem o Estado soberano, cuja crise é irreversível, na medida em que os mercados não mais se alojarão entre os confins estatais. E, por outro lado, problemas globais requerem respostas globais.

A pergunta que devemos responder é se, para além do Estado nacional e das formas a ele conexas da representação popular e do primado da lei estatal, pode existir ou não um futuro para a democracia e para o Estado de Direito; se, em outras palavras, podem ser protegidos, mesmo na crise do Estado, o paradigma do Estado de Direito e o da democracia constitucional. A tese que aqui sustentarei é que ambos os paradigmas poderão ser salvos se forem reforçados e desenvolvidos nos confrontos dos poderes extraestatais que hoje se subtraem ao poder e ao Direito dos Estados. Trata-se de duas perspectivas, ambas difíceis e talvez improváveis, mas das quais depende o futuro seja do Estado de Direito, seja da democracia: por um lado a reabilitação do papel de governo da política por meio da construção de uma esfera pública supranacional - ao menos europeia, mas também internacional - à altura dos novos poderes econômicos globais atualmente desregulados e selvagens; por outro, a garantia da efetividade dos seus limites e dos seus vínculos constitucionais, por meio de uma refundação das formas da representação política e a introdução de rígidos sistemas de incompatibilidades capazes de impedir os conflitos de interesse e de garantir a proibição do mandado imperativo.

\subsection{O futuro do Estado de Direito}

A primeira perspectiva requer o desenvolvimento das formas do Estado de Direito no âmbito internacional e, conjuntamente, no confronto dos poderes econômicos privados. Diante da crise da soberania do Estado e, ainda, aos processos de sujeição da política à economia anteriormente ilustrados, a única alternativa ao fim do Estado de Direito é, justamente, a 
promoção de uma integração jurídica e institucional, em compasso com a já irreversível integração econômica, e o desenvolvimento de um Estado de Direito sem Estado abarcando os poderes econômicos privados e à altura dos novos lugares, não mais estatais, mas extra ou supraestatais para os quais destinaram o poder e as decisões.

Nesta perspectiva a construção de um Estado de Direito supraestatal - no âmbito europeu, e mais ainda no âmbito internacional - requer um percurso inverso àquele completado pelos Estados nacionais: não mais o constitucionalismo como complemento do paradigma juspositivista do Estado Legislativo de Direito, mas ao contrário, a construção do Estado Legislativo de Direito como atuação das promessas constitucionais expressas pelos direitos fundamentais. O Direito supraestatal, de fato, dispõe já de inúmeras cartas e declarações de direitos, regionais e internacionais. $\mathrm{O}$ vazio de um Direito Público supraestatal para o qual acenei anteriormente é, sobretudo, um vazio de garantias de tais direitos, que requerem normas de atuação capazes de preencher as suas lacunas.

Justamente a crise econômica atual poderia representar uma ocasião, em virtude da necessidade e da urgência de provimentos públicos supraestatais capazes de afrontá-la, para completar um novo passo no processo de integração, seja europeu, seja internacional. Nunca como hoje, diante da gravidade da crise, revelou-se a falta dramática de um governo político supranacional da economia, capaz de impor regras, limites e controles aos mecanismos financeiros para impedir-lhes os ataques especulativos. Os remédios projetados para tal carência, em âmbito europeu, como também no plano internacional, são múltiplos e heterogêneos, tão necessários e urgentes quanto, infelizmente, nos tempos atuais improváveis: antes de tudo um programa fiscal europeu e tomara internacional, começando por uma adequada taxação das transações financeiras - como a bem conhecida Tobin Tax - voltada não somente à retirada de recursos públicos, mas também, e sobretudo, à drástica redução, se não a impe- 
dir, das operações puramente especulativas; em segundo lugar, um passo adiante em direção à construção de uma Europa federal e, ao mesmo tempo, social, dotada de um orçamento comum e de comuns políticas econômicas e sociais; em terceiro lugar, a atribuição das avaliações financeiras dos estados, hoje confiadas a agências privadas, à competência de autoridades internacionais, públicas e independentes; em quarto lugar, a subtração ao mercado e às apropriações privadas, mas também à disponibilidade política de bens vitais ou comuns, como o ar, a água, o equilíbrio climático, o patrimônio ambiental, os recursos minerais do fundo dos oceanos, por meio da sua constitucionalização como bens fundamentais, nas Constituições estatais e nos tratados internacionais; em quinto lugar as tendenciais e graduais unificações do Direito do Trabalho e das suas garantias, primeiro no âmbito europeu e, depois, no âmbito mundial; enfim, uma reforma no sentido efetivamente representativo das atuais instituições econômicas - o Fundo Monetário Internacional, o Banco Mundial e a Organização Mundial do Comércio - hoje controladas pelas países mais ricos, para restituir-lhes suas originárias funções estatutárias como desenhadas por John Maynard Keynes: a estabilidade financeira, a ajuda ao desenvolvimento dos países pobres, a promoção do emprego e a redução dos desequilíbrios e das desigualdades, quer dizer, exatamente o oposto das suas prestações modernas, consistentes, por outro lado, nas imposições aos Estados de políticas pesadamente antissociais.

Por outro lado, a necessidade de restaurar também em âmbito estatal as democracias nacionais, a separação moderna da esfera pública em relação à esfera econômica, e o primado da primeira sobre a segunda, e por isso, para impedir a concentração de poderes e conflitos de interesses, requer a introdução de incompatibilidade rígida de poderes políticos e poderes econômicos privados, mas também as garantias secundárias, consistentes no controle de tais incompatibilidades confiadas a órgãos independentes e imparciais. E na velha receita montesquieuana da separação dos poderes que as modernas democracias complexas deveriam investir, 
primeiramente, na relação entre poderes públicos e poderes privados ou sociais: não somente, acrescento, entre a esfera da política e aquela da economia, mas também entre as instituições estatais e os partidos, hoje substancialmente estatizados que deveriam ser restituídos ao seu papel de órgão da sociedade e de instrumentos da participação dos cidadãos à vida política, como sujeitos representados, em vez de representantes, voltados à formulação dos programas à escolha dos candidatos e à responsabilização dos eleitos - por meio da previsão da incompatibilidade entre cargos de partido e cargos eletivos institucionais.

\subsection{O futuro da democracia constitucional}

A clássica receita da separação, porém, é hoje essencial também aos fins da refundação da legalidade constitucional, quer dizer, do segundo paradigma da modernidade anteriormente desenvolvido. Nessa segunda prospectiva, é justamente o modelo do constitucionalismo democrático que sugere a reavaliação do papel da esfera pública, seja no âmbito internacional, seja no âmbito estatal. Diante do desenvolvimento das funções públicas geradas pela garantia dos direitos fundamentais impostos pelas cartas constitucionais nacionais e internacionais, aquilo que se requer é uma atualização da separação montesquieuana dos poderes públicos que deveriam ser estendidos bem além da separação setecentista do poder Judiciário em relação ao poder Legislativo e também do poder Executivo. Reproponho aqui a distinção que mais de uma vez indiquei entre instituições de governo e instituições de garantia: as primeiras investidas de funções políticas de escolha e de inovações em razão daquilo que chamei de “esfera do decidível”, e, por isso, legitimada pela representação popular; as segundas voltadas à garantia dos direitos fundamentais, quer dizer, daquilo que chamei de "esfera do não decidível” e, por isso, legitimada, pela aplicação da lei, seja ordinária ou constitucional. Entre as instituições e as funções de governo, seja o poder Legislativo ou o poder Executivo, 
este último não mais confiado ao soberano, mas expressão, em democracia, da representação política em igualdade com o Legislativo, ao qual está vinculado, nos sistemas parlamentares, pela relação de confiança, entram, em vez, entre as instituições e as funções de garantia, não mais somente as funções jurisdicionais, mas também as funções administrativas, voltadas à garantia em via primária dos direitos sociais, como as instituições escolásticas, aquelas sanitárias, as providenciais e similares.

Esta reformulação da separação entre os poderes públicos é particularmente fecunda aos fins de uma fundação constitucional da esfera pública supraestatal, a qual requer - mais do que o desenvolvimento das funções de governo em vista de um superestado a partir do modelo improvável do Estado representativo nacional - o reforço e a introdução de funções e instituições de garantia dos direitos fundamentais estipulados nas tantas cartas internacionais. Enquanto, de fato, as funções de governo, sendo legitimadas pela representação política, mesmo que permaneçam no âmbito da competência dos Estados nacionais, as funções de garantia, sendo legitimadas pela sujeição à lei e à universalidade dos direitos fundamentais, não somente podem, mas em muitos casos devem - em matéria de proteção do ambiente e de bens ecológicos, de defesa da criminalidade internacional e de redução das desigualdades e da pobreza - ser instituídas no plano internacional. É a falta, ou a ineficácia, destas instituições e funções de garantia de direitos, mesmo estipulados em tantas cartas e declarações, a vistosa lacuna do atual Direito Internacional equivalente a sua violação estrutural. Cada uma destas instituições como aquelas econômicas, antes recordadas, e, por outro lado, a FAO, a Organização Mundial da Saúde e a Corte Penal Internacional existem de há muito e se trataria de reformá-las, de reforçá-las e de dotá-las de meios e de poderes necessários ao exercício de suas funções de garantia. Outras - na perspectiva do ambiente, da segurança e de outras emergências ao mesmo tempo vitais e globais - deveriam, em vez, serem instituídas. E ainda, evidentemente, que para seu funcionamento seria necessária uma fiscalização mundial: 
além da já referida Tobin Tax sobre as transações financeiras, a taxação do uso, do desfrute e, ainda, da danificação de muitos bens comuns - como as órbitas terrestres e os espaços atmosféricos - hoje utilizados pelos países ricos como res nullius.

A mesma separação entre função e instituição de governo e função e instituição de garantia é, por outro lado, essencial aos fins da refundação da democracia constitucional no âmbito estatal. A estrutura da esfera pública do Estado, até agora moldada sobre o velho esquema da tripartição da separação de poderes públicos montesquieuana, determinou o inteiro desenvolvimento do Estado social e das suas prestações por meio dos aparatos burocráticos do poder Executivo. As funções de garantia primária dos direitos sociais - como os direitos à saúde, à educação, à previdência e à subsistência - não podendo, obviamente, ser organizadas dentro do poder Legislativo ou do poder Judiciário, foram todas colocadas dentro daquele grande e indistinto recipiente que é a administração pública, na dependência do poder Executivo ou de governo. Daí a prática do spoils system, da lotação partidária e dos condicionamentos políticos das funções e das instituições de garantia - a sanidade pública, a escola, os institutos de previdência e de assistência - cuja legitimação política, ao contrário, reside não justamente no consenso dos contingentes majoritários, mas sim na aplicação da lei para a garantia dos direitos de todos. É por força desta diferente fonte de legitimação, não majoritária, mas garantista, que a separação e a independência destas instituições e funções de garantia, que chamei de "primárias", pois destinadas à satisfação em via primária dos correlativos direitos sociais, são, de toda forma, necessárias no modelo da democracia constitucional, como a separação e a independência das instituições e das funções jurisdicionais, que chamei de "secundárias", pois intervêm em caso de violação das garantias primárias. Somente desse modo, por meio da atuação igual e imparcial, pela obra das instituições independentes, das garantias correspondentes aos direitos fundamentais, é possível a transformação do moderno Estado social burocrático 
com todas as suas ineficiências, em um Estado social e constitucional de Direito. É claro que para as funções políticas de governo estariam confiadas a organização e o financiamento das instituições de garantia, como hoje acontece na Itália com as competências do Ministério da Justiça em relação à instituição judiciária. Seria necessária, porém, a garantia da complementação do aparato garantista contra os descumprimentos legislativos e governativos, a obrigação, introduzida, por exemplo, pela Constituição Brasileira de respeitar precisos vínculos fiscais impostos pela estipulação constitucional de cotas mínimas da despesa pública reservada à satisfação dos diversos direitos sociais.

É, pois, evidente que todas as separações anteriormente elencadas - entre poderes econômicos e poderes políticos, entre o poder social dos partidos e o poder político das instituições de governo, entre funções e instituições de governo e funções e instituições de garantia - viriam a contrastar a onipotência das maiorias que como se viu está hoje ameaçando a manutenção das nossas democracias constitucionais. "É um dado de experiência eterna”, observa Montesquieu, que qualquer poder em ausência de limites, degenera em poder absoluto e selvagem: daí, "para que não se possa abusar do poder, é necessário, que, para a disposição das coisas, o poder freie o próprio poder": que o poder público, em outras palavras, seja fragmentado e separado e que os poderes e as funções de garantia freiem os poderes de governo, em atuação dos limites e dos vínculos a eles impostos pelos direitos constitucionalmente estipulados. Por outro lado, o impedimento da onipotência das maiorias e das derivações populistas requerem, outrossim, como a experiência italiana ensina, a reabilitação do papel dos parlamentos, a vinculação a sua confiança no poder Executivo e a restauração da mediação representativa governo e eleitorado e da proibição de mandado imperativo, ambos favorecidos pelo sistema eleitoral proporcional e frustrados, por outro lado, pela redução das eleições destacada pelos sistemas variamente bipolares e majoritários, à investidura popular de uma maioria e do seu chefe. 
Naturalmente, os processos degenerativos em andamento não comportam nenhum otimismo, todavia devemos ser conscientes que em tais processos não existe nada de natural; e que a democracia, nas suas diversas e complexas formas, dimensões e níveis, é uma construção artificial que depende da política das lutas sociais para a sua sustentação e, também, do papel crítico e projetural da ciência jurídica e política. Por isso, em relação ao futuro do Estado de Direito e da democracia constitucional somos todos, em várias medidas, responsáveis.

Recebido em: 20/5/2013

Aceito em: 20/5/2013

Autor convidado. 